\title{
From asthma severity to control: a shift in clinical practice
}

\author{
* Søren Pedersen ${ }^{a}$ \\ a Pediatric Research Unit, Kolding Hospital, Kolding, Denmark
}

Received 18th May 2009; revised version received 18th June 2009; accepted 18th July 2009; online 16th October 2009

\begin{abstract}
Variability is a characteristic feature of asthma, and the aim of asthma management is to eliminate or minimise disease variability. Controlled asthma shows little or no variability, and is achievable and sustainable in the majority of patients. New international guidelines recommend control-driven management rather than management based on disease severity. Good asthma control is associated with reductions in patients' perception of the asthma burden, reduced healthcare resource utilisation, lower levels of impairment/restriction, normal quality of life, and low risk of exacerbations. Asthma control involves the control of several outcomes. Its assessment should include components relevant to achievement of best possible clinical control and reduction of future risk of adverse outcomes. Focusing on a single or a few outcomes can lead to incorrect control assessment and increased risk of under-treatment. Several validated asthma control assessment tools have been developed to facilitate correct assessment of the level of control in clinical practice. It is hoped that focusing on control will reduce the frequency of sub-optimal treatment in the primary care setting. Further validation of the best way to assess control easily and accurately, and the implementation of control-driven management, are the two most important challenges for the future of asthma management.

(C) 2010 Primary Care Respiratory Society UK. All rights reserved.

S Pedersen. Prim Care Resp J 2010; 19(1): 3-9.

doi:10.4104/pcrj.2009.00059
\end{abstract}

Keywords asthma, control, assessment, severity, variability, treatment, management, primary care

\section{Contents}

Introduction

Why 'control' rather than 'severity'?

Asthma control is achievable in most patients

Level of asthma control is important

How should asthma control be defined and assessed?

References

\section{Introduction}

The initial Global INitiative for Asthma (GINA) treatment guideline published in 1993 was based on disease severity grading: intermittent, mild persistent, moderate persistent and severe persistent asthma. Since then several studies have shown that guideline-defined asthma control is achievable in most patients, and that achievement of good control is associated with improved health status. ${ }^{1-3}$ Therefore, in the latest GINA guideline, treatment recommendations are based on the level of asthma control rather than disease severity. ${ }^{4}$ In the control-driven approach, the attainment and maintenance of asthma control are the key elements that drive patient management. ${ }^{4}$ To achieve this, patients should be assessed, and treatment tailored and adjusted in regular cycles based on their asthma control status (see Figure 1). When the condition is not controlled, treatment should be stepped up until control is achieved and maintained for at least three months, at which point a step down in treatment can be considered.

This paper presents the background for the change in treatment approach adopted by the GINA guideline. The area is complex since there are no consistently accepted definitions for asthma control, severity, or exacerbations. However, some useful definitions have recently been recommended by a joint

\footnotetext{
* Corresponding author: Professor Søren Pedersen, Pediatric Research Unit, Kolding Hospital, Skovvangen 2- 8, Kolding, 6000, Denmark Tel: +45 76362223 Fax: +45 76363479 E-mail: spconsult@post1.tele.dk
} 
Figure 1. Asthma management: A treatment algorithm based on GINA guidelines. ${ }^{4}$ In partially controlled patients the decision to step up treatment is influenced by the level of treatment the patient is already receiving and the patient's demands. If partial control has been achieved on a low daily dose of inhaled corticosteroid, stepping up the daily controller treatment is more likely than if the patient is partially controlled on a high daily controller treatment or if they are using multiple drugs. The control level should be re-assessed regularly (every 3-6 months) and at each assessment it should be decided whether the current treatment should be continued or stepped down.

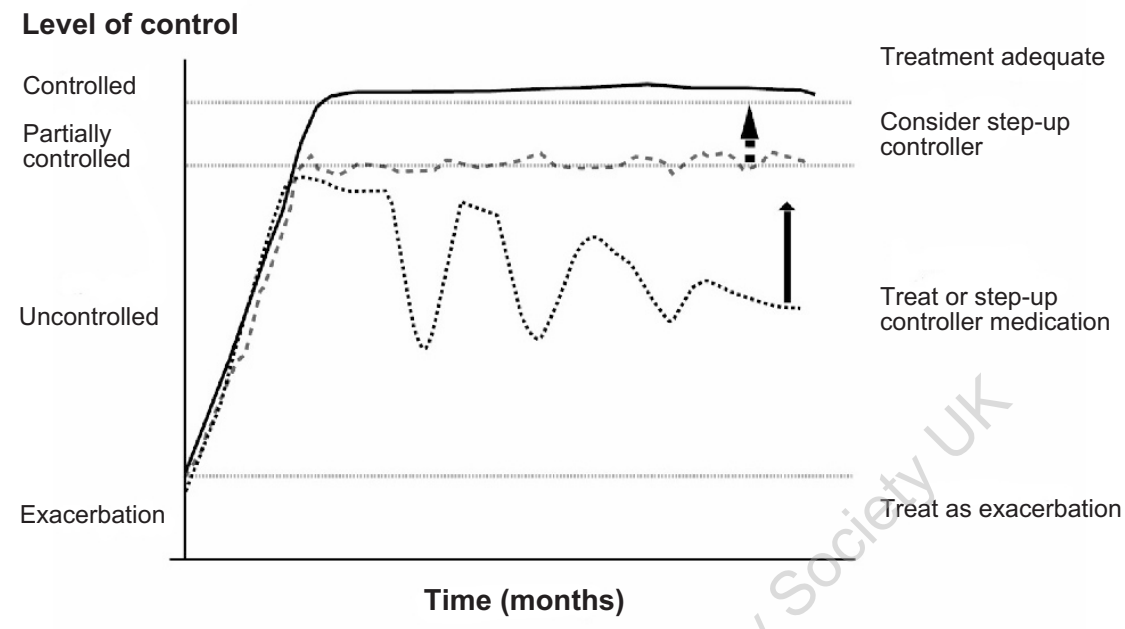

task force of the American Thoracic Society (ATS) and European Respiratory Society (ERS): ${ }^{5}$

- Asthma severity is defined as the difficulty in controlling asthma with treatment after exclusion of modifiable factors such as poor adherence, smoking, and co-morbidities. Severity largely reflects the required level of treatment and the activity of the underlying disease state during treatment.

- Asthma control encompasses not only the patient's recent clinical state (symptoms, night waking, reliever use, and lung function), but also considers their "future risk" - that is, their potential for experiencing adverse outcomes, such as loss of control in the near or distant future, exacerbations, accelerated decline in lung function, or treatment-related side effects. It is emphasised that even if current poor control predicts future poor control and health care utilisation, other pathologic and physiologic measures, independent of the level of current clinical control, also influence future risk. ${ }^{5}$

\section{Why 'control' rather than 'severity'?}

Severity grading is complex and not widely used in clinical practice. ${ }^{6,7}$ Cross-sectional surveys from various countries have shown that the use of inhaled corticosteroids (ICS) and quick reliever medications is independent of patients' asthma severity grading. ${ }^{8,9}$ No correlation is seen between asthma severity and regular use of ICS. In a European survey of patients with persistent asthma symptoms, ICS were used by only $25 \%$ of adults with severe asthma, $23 \%$ of those with moderate asthma and $28 \%$ of those with mild asthma; the corresponding figures for children were $26 \%, 33 \%$ and $33 \%$, respectively. ${ }^{8}$ Similar findings indicative of poor asthma control and a lack of correlation between ICS use and severity were recorded in 3207 patients interviewed across the Asia-Pacific region in the Asthma Insights and Reality in Asia-Pacific (AIRAP) study. ${ }^{9}$ In this study, the use of ICS was $18 \%, 17 \%, 13 \%$ and $12 \%$ in severe persistent, moderate persistent, mild persistent and mild intermittent ${ }^{7}$ asthma patients, respectively. Patients often underestimate disease severity and overestimate control, with the result that $50 \%$ of those interviewed in the European study with severe and persistent asthma symptoms considered their condition to be completely or well controlled despite poor health status and high levels of healthcare resource utilisation. ${ }^{8}$

Asthma severity is not fixed. It fluctuates over time and is enhanced by various trigger factors such as seasonal allergen exposure, infections and treatment. Thus, over a three-month period, placebo-treated patients with moderate asthma severity at baseline could be classified as having severe asthma $6 \%$ of the time, mild asthma $14 \%$ of the time, and intermittent asthma $9 \%$ of the time. ${ }^{10}$

Accurate disease severity assessment is even more complex in patients who are already on regular controller medication. ${ }^{11}$ Liard and colleagues used the GINA guideline to define asthma severity in more than 4000 patients and found that the classification rules were complex and not clinically useful because of frequent over- and under-estimation of severity, even when a "symptom + forced expiratory volume in one second $\left(\mathrm{FEV}_{1}\right)+$ medication" classification was used. ${ }^{11}$ Respiratory specialists have been reported to disagree markedly when classifying asthma severity. ${ }^{12,13}$ The differences between severity and control have recently been discussed in detail. .,14 $^{14}$

Patients with severe symptoms and impairment (particularly 
children) can still have normal lung function. ${ }^{12,13,15-17}$ This discord between the clinical presentation and level of lung function which is an important factor in the severity grading - can complicate the assessment of severity, leading to underestimation of disease severity and under-treatment with subsequent poor asthma control. This may contribute to the findings that a substantial number of children with fatal asthma exacerbations had been assessed as having mild disease and were not prescribed regular controller treatment. ${ }^{12,13}$ Thus, in one study of 61 patients (mainly children) who experienced fatal asthma exacerbations over a 7-year period, only $5 \%$ of those who died were using long-term control medications. ${ }^{12}$

\section{Asthma control is achievable in most patients}

Clinical evidence suggests that good asthma control is achievable for the vast majority of patients, including adults and adolescents. ${ }^{23,18}$ In one study, adult and adolescent patients with markedly uncontrolled asthma were treated with either fluticasone propionate (FP) or salmeterol plus FP combination (SFC) for 1 year ${ }^{18}$ to assess the proportion of patients that could achieve total- or well-controlled asthma. The vast majority of the patients had severe persistent asthma at study entry. The level of control was defined by a composite measure (based on international guidelines) that included daytime symptoms, use of rescue medication, peak expiratory flow, night-time awakening, exacerbations, emergency room visits and treatment-related adverse events. Treatment was stepped up at 3-month intervals until either patients achieved total control or the maximum dose of study medication (1000 mcg FP per day) was reached. At the end of the study period, approximately $70 \%$ of patients had asthma that was either well controlled or totally controlled. Moreover, improvements in at least one clinical outcome were seen in more than $90 \%$ of patients classified as not wellcontrolled. ${ }^{2}$ Present and former smoking was identified as the most important factors for not achieving control. ${ }^{2}$ Further analysis showed that in patients who were ICS-naïve at study entry, and who achieved total asthma control and maintained this control status over long periods, only $2.8 \%$ had reverted to being not well-controlled $(2.8 \%) .{ }^{19}$ These results confirmed that, in the vast majority of patients control can be maintained as long as the treatment is continued.

Other large studies in children and adults have corroborated these findings for mild and moderate asthma. ${ }^{3,20}$ In the inhaled Steroid Treatment As Regular Therapy in early asthma (START) study, regular asthma treatment with budesonide for three years resulted in long-term symptom resolution in more than $90 \%$ of patients, and during the last year of the study the number of exacerbations was negligible. ${ }^{3}$ In the CAMP study budesonide treatment for 4.5 years reduced the number of days with symptoms to less than two per week, and the need for rescue medication from 10 to three puffs per week. In addition the number of nocturnal awakenings was reduced to negligible levels. ${ }^{20}$

\section{Level of asthma control is important}

A characteristic feature of asthma is the variability of the condition with marked fluctuations in symptoms and asthma control over time. An important aim of asthma management, therefore, is to minimise disease variability to enable patients to live a healthy life. The GOAL study demonstrated that this is achievable in the majority of patients; around $90 \%$ of the patients who achieved well-controlled or totally controlled asthma during phase 1 of the study remained at least wellcontrolled at the end of the one-year study and in these patients exacerbations were very rare $\left(<0.4 \%\right.$ probability). ${ }^{19}$ Importantly, disease stability was independent of the medication taken (FP or SFC) or disease severity. Only the level of asthma control was important for the stability of the disease and the risk of having an exacerbation (see Figure 2).

In agreement with these findings, other studies have shown that the use of healthcare resources, the level of lifestyle impairment, and quality of life, are all closely linked to the level of asthma control: the better the control, the less impairment, the lower the use of healthcare resources, and the higher the quality of life. ${ }^{1,2-28} \mathrm{~A}$ 2-year assessment of approximately 4000 patients with difficult-to-treat or severe asthma reported that patients with uncontrolled asthma experienced a higher annual mean number of work days lost (7.1 vs 0.4 ), school days lost (9.1 vs 0.1 ) and physician visits (5.6 vs 2.4), compared with patients who had controlled asthma. ${ }^{24}$ Furthermore, the costs associated with the condition were directly related to the level of control; costs for uncontrolled patients were more than twice the costs of controlled patients (US\$14,212 vs US $\$ 6452 ; P<0.0001$ ). These findings were corroborated in a recent report by Chapman et al. in approximately 10,500 patients presenting in general practices in Canada; ${ }^{21}$ poor daily control was associated with more hospitalisations, emergency room visits, unscheduled doctor visits and other healthcare contacts.

Most of these studies emphasised the importance of the level of asthma control rather than the disease severity or treatment modality for the quality of life, risk of exacerbations, burden of disease and impairment in lifestyle. Thus, patients with severe asthma will experience the same quality of life and disease stability as patients with mild disease providing that their level of asthma control is similar. The achievement of asthma control in the two groups (severe or mild asthma) may require different treatment intensities, but the impact of the disease on daily lifestyle is likely to be the same after the disease has become controlled. Thus, the level of control is a good predictor of a variety of asthma outcomes that are clinically important to both the patient and society. 
Figure 2. The influence of the level of asthma control on the risk of having an asthma exacerbation in patients treated with fluticasone propionate (blue bars) or fluticasone propionate-serevent combination (purple bars)..$^{13}$ The level of asthma control determined the risk of having an exacerbation - the better the control the lower the risk. In patients at the same asthma control level the risk of an exacerbation was independent of the medication taken (though more patients on the combination treatment achieved well and totally controlled asthma. Similarly, the use of healthcare resources, the level of lifestyle restrictions and quality of life have been closely linked to the level of asthma control: the better the control, the less the impairment, the lower the use of healthcare resources, and the higher the quality of Iife.

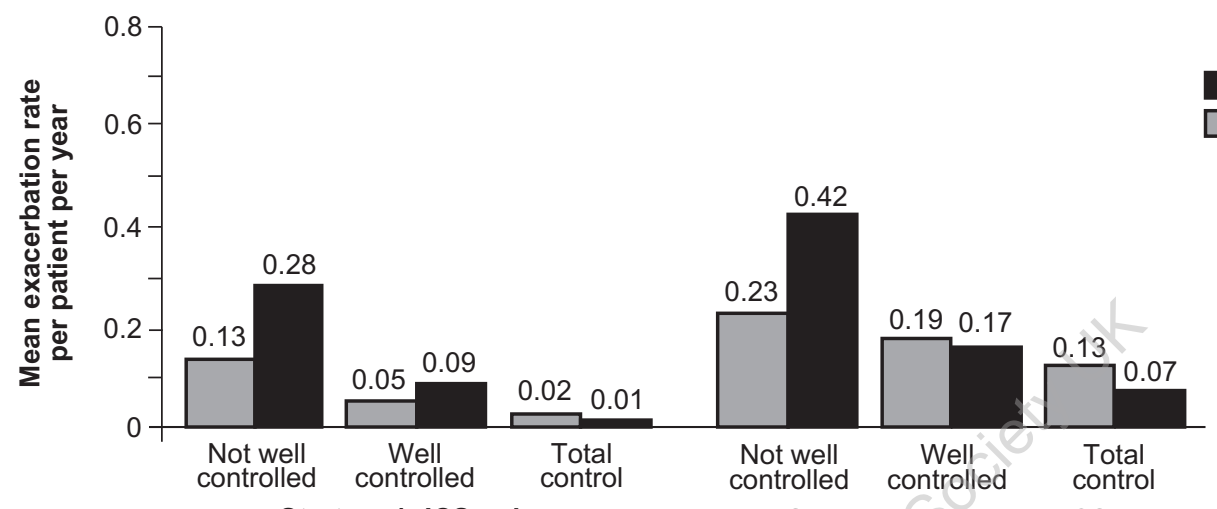

Stratum 1: ICS-naive

Stratum 3: Moderate ICS

\section{How should asthma control be defined and assessed?}

When a new parameter (control level) is used to guide treatment, the definition of asthma control becomes important. As mentioned previously, physicians and patients tend to overestimate the level of asthma control.8,9,21,29,30 Moreover, physicians use various parameters to assess control and, therefore, might evaluate control differently. ${ }^{29,31}$ Unless a control definition that is clinically relevant and easy to use for both healthcare professionals and patients in daily management is developed, the risk of under-treatment will still remain. Therefore, several validated scoring systems and control definitions that fulfil these criteria have been developed to facilitate accurate measurement of the level of asthma control. ${ }^{23,30-34}$ Some, but not all of these instruments include measures of lung function. ${ }^{6}$ All include a combination of several clinical variables to assign a composite score to distinguish between the different levels of asthma control and some are being positioned for use by patients, and are available on the internet and in several languages.

From the validation of the various asthma control tests, and from the findings in the GOAL study ${ }^{19}$, it has become clear that focusing on a single or a few outcomes can lead to overassessment of control with a subsequent risk of undertreatment. ${ }^{35}$ Different outcomes may require different treatment intensities, and the rate of response of individual asthma measures varies. Therefore, evaluation of control using any single measure is likely to overestimate asthma control. Thus, after 12 weeks of treatment in the GOAL study, the proportion of patients who achieved control of an individual clinical criterion was always higher than the proportion who achieved control defined by a composite measure (no nocturnal awakenings was achieved by around 70\%; a peak expiratory flow (PEF) $\geq 80 \%$ predicted every day was achieved by around 50\%; no rescue medication use was reported in 42\%; no daytime symptoms were in $30 \%$ ). In contrast, total control defined by a composite measure was achieved by only around $18 \%$ at that time. This supports the idea that treatment should be continued until composite control is reached rather than control of one or a few individual outcomes.

Focusing on a single outcome, however, might not lead to improvements in other endpoints and could therefore result in under-treatment (Figures 3 and 4). This is illustrated by the findings in a recent 12-month, double-blind study in patients with symptomatic asthma treated with budesonide/formoterol morning and evening plus reliever therapy with either budesonide/formoterol, formoterol alone or terbutaline alone. ${ }^{36}$ Time to first severe exacerbation (the primary endpoint) was significantly longer and the rate of severe exacerbations was markedly lower in the as-needed budesonide/formoterol group compared with those treated with formoterol or terbutaline alone. Statistically significant improvements were also seen in other outcomes - however, compared with the effects on exacerbations these effects were small. Patients treated with the budesonide/formoterol as-needed combination experienced 1.1 mild exacerbations per week, nocturnal awakening on one night per week, and had uncontrolled asthma for two out of three days. So, in spite of a good effect on the frequency of severe exacerbations the majority of patients still had uncontrolled asthma as defined by a composite score. As a result, no effect 
Figure 3. Frequency of different asthma outcomes used in clinical trials. Outcomes at the top of the pyramid are very serious but also very rare compared with the outcomes in the lower part of the pyramid. Thus for each time one severe exacerbation is seen in large clinical trials around $\mathbf{5 0}$ mild exercabations and 300 days with poor asthma control will occur in that study population. The ratios between the various outcomes have been calculated from data in published clinical studies including more than 10,000 patients. It is obvious that symptoms are by far the most common problem for the patients. Controlling symptoms will also reduce the risk of mild and severe exacerbations and improve the patient's quality of life. Therefore, control of daily symptoms is an important outcome in asthma management.

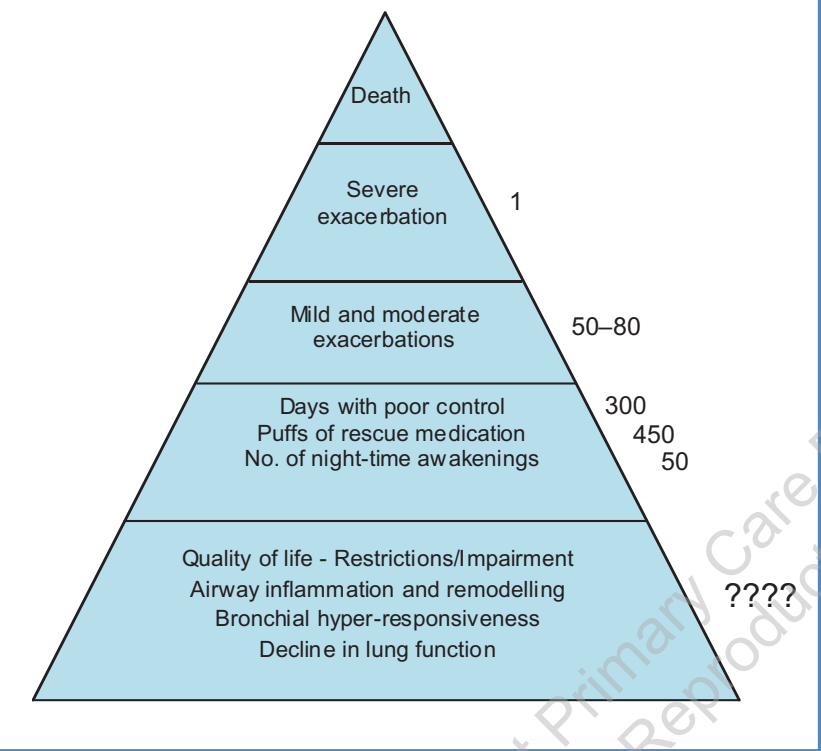

was seen on the patients' asthma quality of life questionnaire in which only $30 \%$ of patients scored normal values.

Given these findings, composite measures of control controlled, partially controlled or uncontrolled asthma - are recommended in the latest GINA guideline. The components of control include daytime symptoms, limitations of activities, nocturnal symptoms/awakening, the need for reliever/rescue medication, lung function and exacerbations (Table 1). ${ }^{37}$ Although these guidelines considered the recommendations as being a non-validated working model at the time of publication, composite measures of totally controlled and well-controlled asthma based on GINA and the National Institute of Health guidelines have more recently been validated as functional indices of disease control. ${ }^{38,39}$ The study by Thomas and colleagues found that an ACT score of $<19$ correctly predicted GINA-defined partly controlled/uncontrolled asthma $94 \%$ of the time, while an ACT score of $>20$ predicted GINA-defined controlled asthma only $51 \%$ of the time. ${ }^{40}$ Thus, a normal ACT score did not exclude poor asthma control whereas a reduced
Figure 4. Importance of using a composite score rather than a single outcome such as exacerbations when assessing the effect of treatment and the level of asthma control illustrated by one case. The black line illustrates the situation before treatment. The patient is uncontrolled most of the time and experiences 5 exacerbations over a year. After treatment (gray line) there are no longer any exacerbations and the clinical condition is markedly improved. However, when the control level is assessed using the outcomes recommended in Table 1 it becomes obvious that the disease, in spite of the marked improvements, is still insufficiently controlled and further adjustment of treatment warranted.

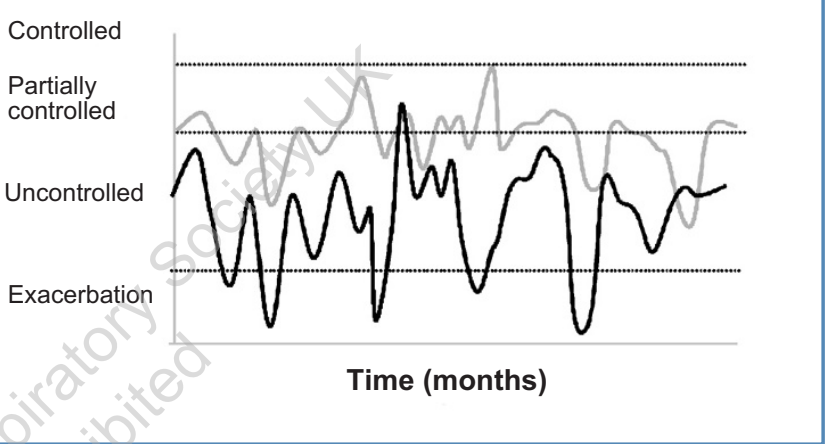

score strongly suggested poor asthma control. When exacerbations were removed from the definition of asthma control, a score $>20$ predicted GINA-defined asthma control $71.6 \%$ of the time. Therefore, more work is needed to assess how best to use exacerbations in the definition of, and how to define the best and most simple way to assess, asthma control in clinical practice - in particular in children and in patients with mild asthma, many of whom have adapted their lifestyle to ensure fewer symptoms at the expense of limiting activities in their daily life.

The joint ATS/ERS Task Force has recently listed a variety of asthma outcomes relevant for control assessment in the daily clinic. $^{5}$ These include symptom-free days (symptom/reliever/lung

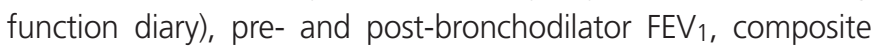
scores, quality of life, treatment side-effects and exacerbations (oral steroids, emergency room visits and hospitalisations within last four weeks).

Although the present recommendations are likely to make the assessment of control easier, it has not yet been demonstrated how to resolve patients' poor perception of asthma symptoms. Therefore, overcoming the obstacles with accurate assessment and implementation of control-driven treatment constitute some important challenges for the future. It is hoped that the focus on control will reduce the frequency of sub-optimal treatment in the primary care setting. Recent findings suggest that lack of control can be recognised by physicians in general practice with the use of standardised 
Table 1. Levels of asthma control according to the GINA guidelines. ${ }^{4}$

\begin{tabular}{|c|c|c|c|}
\hline Characteristic & $\begin{array}{l}\text { Controlled } \\
\text { (all of the following) }\end{array}$ & $\begin{array}{l}\text { Partially controlled } \\
\text { (any measure present in any week) }\end{array}$ & Uncontrolled \\
\hline Daytime symptoms & None (twice or less/week) & More than twice/week & Three or more \\
\hline Limitations of activities & None & Any & features of partially \\
\hline Nocturnal symptoms/awakening & None & Any & controlled asthma \\
\hline Need for reliever/rescue treatment & None (twice or less/week) & More than twice/week & present in any week \\
\hline Exacerbations & None & One or more/year* & One in any week ${ }^{\dagger}$ \\
\hline
\end{tabular}

*Any exacerbation should prompt review of maintenance treatment to ensure that it is adequate

tBy definition, an exacerbation in any week makes that an uncontrolled asthma week

fLung function is not a reliable test for children $\leq 5$ years of age

$\mathrm{FEV}_{1}$, forced expiratory volume in one second; GINA, Global INitiative for Asthma; PEF, peak expiratory flow.

questionnaires - and then, after control status has been identified, the physician is likely to consider appropriate changes to therapy. ${ }^{21}$

\section{Conflict of interest}

Over the last 3 years SP has given talks or participated in advisory boards for Nycomed, GlaxoSmithKline, NeoLab and Boeringer Ingelheim.

\section{References}

1. Bateman ED, Bousquet J, Keech ML, Busse WW, Clark TJ, Pedersen SE. The correlation between asthma control and health status: the GOAL study. Eur Respir J 2007;29(1):56-62. http://dx.doi.org/10.1183/09031936.00128505

2. Pedersen SE, Bateman ED, Bousquet J, Busse WW, Yoxall S, Clark TJ. Determinants of response to fluticasone propionate and salmeterol/fluticasone propionate combination in the Gaining Optimal Asthma controL study. A Allergy Clin Immunol 2007;120(5):1036-42. http://dx.doi.org/10.1016/ j.jaci.2007.07.016

3. Pauwels RA, Pedersen S, Busse WW, et al. Early intervention with budesonide in mild persistent asthma: a randomised, double-blind trial. Lancet 2003; 361(9363):1071-6. http://dx.doi.org/10.1016/S0140-6736(03)12891-7

4. Global Initiative for Asthma (GINA). Global Strategy for Asthma Management and Prevention. http://www.ginasthma.com/GuidelinesResources.asp . 2007.

5. Reddel HK, Taylor DR, Bateman ED, et al. An Official American Thoracic Society/European Respiratory Society Statement: Asthma Control and Exacerbations: Standardizing Endpoints for Clinical Asthma Trials and Clinical Practice. Am J Respir Crit Care Med 2009;180:59-99. http://dx.doi.org/10.1164/rccm.200801-060ST

6. Birnbaum HG, Ivanova JI, Yu AP, et al. Asthma severity categorization using a claims-based algorithm or pulmonary function testing. I Asthma 2009; 46(1):67-72.

7. Colice GL. The seduction of asthma severity categorization. Chest 2003; 124(6):2054-6. http://dx.doi.org/10.1378/chest.124.6.2054

8. Rabe KF, Vermeire PA, Soriano JB, Maier WC. Clinical management of asthma in 1999: the Asthma Insights and Reality in Europe (AIRE) study. Eur Respir J 2000; 16(5):802-07.

9. Lai CK, De Guia TS, Kim YY, et al. Asthma control in the Asia-Pacific region: the Asthma Insights and Reality in Asia-Pacific Study. J Allergy Clin Immunol 2003; 111(2):263-8. http://dx.doi.org/10.1067/mai.2003.30

10. Calhoun WJ, Sutton LB, Emmett A, Dorinsky PM. Asthma variability in patients previously treated with beta2-agonists alone. I Allergy Clin Immunol 2003;
112(6):1088-94. http://dx.doi.org/10.1016/j.jaci.2003.09.044

11. Liard R, Leynaert B, Zureik M, Beguin FX, Neukirch F. Using Global Initiative for Asthma guidelines to assess asthma severity in populations. Eur Respir J 2000: 16(4):615-20.

12. Becker JM, Rogers J, Rossini G, Mirchandani H, D'Alonzo GE, Jr. Asthma deaths during sports: report of a 7-year experience. I Allergy Clin Immunol 2004; 113(2):264-7. http://dx.doi.org/10.1016/j.jaci.2003.10.052

13. Robertson C, Rubinfeld A, Bowes G. Deaths from asthma in Victoria: a 12month survey. Med J Aust 1990;152:511-17.

14. Taylor DR, Bateman ED, Boulet $L P$, et al. A new perspective on concepts of asthma severity and control. Eur Respir J 2008;32(3):545-54. http://dx.doi.org/10.1183/09031936.00155307

15. Jenkins HA, Cherniack R, Szefler SJ, Covar R, Gelfand EW, Spahn JD. A comparison of the clinical characteristics of children and adults with severe asthma. Chest 2003;124(4):1318-24. http://dx.doi.org/10.1378/ chest.124.4.1318

16. Paull K, Covar R, Jain N, Gelfand EW, Spahn JD. Do NHLBl lung function criteria apply to children? A cross-sectional evaluation of childhood asthma at National Jewish Medical and Research Center, 1999-2002. Pediatr Pulmonol 2005; 39(4):311-17. http://dx.doi.org/10.1002/ppul.20161

17. Spahn JD, Cherniack R, Paull K, Gelfand EW. Is forced expiratory volume in one second the best measure of severity in childhood asthma? Am J Respir Crit Care Med 2004;169(7):784-6. http://dx.doi.org/10.1164/rccm.200309-1234OE

18. Bateman ED, Boushey HA, Bousquet J, et al. Can guideline-defined asthma control be achieved? The Gaining Optimal Asthma ControL study. Am J Respir Crit Care Med 2004;170(8):836-44. http://dx.doi.org/10.1164/rccm.2004010330C

19. Bateman ED, Bousquet J, Busse WW, et al. Stability of asthma control with regular treatment: an analysis of the Gaining Optimal Asthma controL (GOAL) study. Allergy 2008;63(7):932-8. http://dx.doi.org/10.1111/j.13989995.2008.01724.x

20. Long-term effects of budesonide or nedocromil in children with asthma. The Childhood Asthma Management Program Research Group [see comments]. New Engl J Med 2000;343:1054-63. http://dx.doi.org/10.1056/ NEJM200010123431501

21. Chapman KR, Boulet LP, Rea RM, Franssen E. Suboptimal asthma control: prevalence, detection and consequences in general practice. Eur Respir J 2008; 31(2):320-5. http://dx.doi.org/10.1183/09031936.00039707

22. Vollmer WM, Markson LE, O'Connor E, Frazier EA, Berger M, Buist AS. Association of asthma control with health care utilization: a prospective evaluation. Am J Respir Crit Care Med 2002;165(2):195-9. 
23. Vollmer WM, Markson LE, O'Connor E, et al. Association of asthma control with health care utilization and quality of life. Am J Respir Crit Care Med 1999; 160(5 Pt 1):1647-52.

24. Sullivan SD, Rasouliyan L, Russo PA, Kamath T, Chipps BE. Extent, patterns, and burden of uncontrolled disease in severe or difficult-to-treat asthma. Allergy 2007;62(2):126-33. http://dx.doi.org/10.1111/j.1398-9995.2006.01254.x

25. Sullivan SD, Wenzel SE, Bresnahan BW, et al. Association of control and risk of severe asthma-related events in severe or difficult-to-treat asthma patients. Allergy 2007;62(6):655-60. http://dx.doi.org/10.1111/j.1398-9995. 2007.01383.x

26. Schatz M, Mosen D, Apter AJ, et al. Relationships among quality of life, severity, and control measures in asthma: an evaluation using factor analysis. $J$ Allergy Clin Immunol 2005;115(5):1049-55. http://dx.doi.org/10.1016/j.jaci. 2005.02.008

27. Chen H, Gould MK, Blanc PD, et al. Asthma control, severity, and quality of life: quantifying the effect of uncontrolled disease. J Allergy Clin Immunol 2007; 120(2):396-402. http://dx.doi.org/10.1016/j.jaci.2007.04.040

28. Weiss K, Buxton M, Andersson FL, Lamm CJ, Liljas B, Sullivan SD. Costeffectiveness of early intervention with once-daily budesonide in children with mild persistent asthma: results from the START study. Pediatr Allergy Immunol 2006;17 Suppl 17:21-7.

29. Boulet LP, Phillips R, O'Byrne P, Becker A. Evaluation of asthma control by physicians and patients: comparison with current guidelines. Can Respir J 2002; 9(6):417-23.

30. Leuppi JD, Steurer-Stey C, Peter M, Chhajed PN, Wildhaber JH, Spertini F. Asthma control in Switzerland: a general practitioner based survey. Curr Med Res Opin 2006;22(11):2159-66. http://dx.doi.org/10.1185/ $030079906 \times 148454$

31. Boulet LP, Boulet V, Milot J. How should we quantify asthma control? A proposal. Chest 2002;122(6):2217-23. http://dx.doi.org/10.1378/ chest.122.6.2217

32. Lenoir M, Williamson A, Stanford RH, Stempel DA. Assessment of asthma control in a general population of asthmatics. Curr Med Res Opin 2006; 22(1):17-22. http://dx.doi.org/10.1185/030079905X74925

33. Juniper EF, Buist AS, Cox FM, Ferrie PJ, King DR. Validation of a standardized version of the Asthma Quality of Life Questionnaire. Chest 1999;115(5):126570. http://dx.doi.org/10.1378/chest.115.5.1265

34. Nathan RA, Sorkness CA, Kosinski M, et al. Development of the asthma control test: a survey for assessing asthma control. J Allergy Clin Immunol 2004; 113(1):59-65. http://dx.doi.org/10.1016/j.jaci.2003.09.008

35. Bateman ED, Clark TJ, Frith L, Bousquet J, Busse WW, Pedersen SE. Rate of response of individual asthma control measures varies and may overestimate asthma control: an analysis of the GOAL study. J Asthma 2007;44(8):667-73. http://dx.doi.org/10.1080/02770900701554821

36. Rabe KF, Atienza T, Magyar P, Larsson P, Jorup C, Lalloo UG. Effect of budesonide in combination with formoterol for reliever therapy in asthma exacerbations: a randomised controlled, double-blind study. Lancet 2006; 368(9537):744-53. http://dx.doi.org/10.1016/S0140-6736(06)69284-2

37. Bateman ED, Hurd SS, Barnes PJ, et al. Global strategy for asthma management and prevention: GINA executive summary. Eur Respir J 2008;31(1):143-78. http://dx.doi.org/10.1183/09031936.00138707

38. Spencer S, Mayer B, Bendall KL, Bateman ED. Validation of a guideline-based composite outcome assessment tool for asthma control. Respir Res 2007;8:26. http://dx.doi.org/10.1186/1465-9921-8-26

39. Thomas M, Kay S, Pike J, et al. The Asthma Control Test (ACT) as a predictor of GINA guideline-defined asthma control: analysis of a multinational crosssectional survey. Prim Care Resp J 2009;18(1):41-9. 